\title{
Evaporation calculations for Lake Sennar (Sudan): a search for a meteorological minimum input approach for shallow lakes
}

\author{
B. I. ABDULAI ${ }^{1}$, C. J. STIGTER ${ }^{2}$, A. A. IBRAHIM ${ }^{3}$, A. M. ADEEB ${ }^{4} \&$ H. S. \\ ADAM $^{5}$ \\ 1 Irrigation Development Authority, Accra, Ghana \\ 2 TTMI-Project, c/o Department of Meteorology, Wageningen Agricultural University, \\ Wageningen, Netherlands \\ 3 Hydraulics Research Station, Wad Medani, Sudan \\ ${ }^{4}$ Faculty of Agricultural Sciences, Department of Agricultural Engineering, University of \\ Gezira, Wad Medani, Sudan \\ 5 Faculty of Agricultural Sciences, Department of Environmental Sciences and Natural \\ Resources, University of Gezira, Wad Medani, Sudan
}

Received 18 September 1989; accepted 3 July 1990

\begin{abstract}
A simplification for lake evaporation calculations in the tropics is proposed by replacing the aerodynamic term in the Penman open water evaporation equation with a relation developed between shaded Piche evaporation rate and this aerodynamic term, using Penman's revised wind function over water as earlier selected by Stigter from a comparison of wind functions. Evaporation rates from lake Sennar (Sudan) were further calculated with four more equations that have their formulations based on Penman's equation. Meteorological input data were collected from three stations in Sennar area: on the lake, at the shore and at the regular meteorological station. The Stewart \& Rouse approach and the proposed simplification using the shaded Piche appear promising in the search for a minimum meteorological input approach.
\end{abstract}

Keywords: lake evaporation, Penman's equation, shaded Piche evaporation

\section{Introduction}

Better estimation of lake evaporation improves water availability calculations, which are for example extremely important for all countries sharing the water of the Nile. In most tropical countries, water balance methods of estimating lake evaporation rates are operationally difficult and inaccurate. Indirect meteorological methods remain therefore the only techniques for such conditions. The Penman open water evaporation formula is the most widely used indirect method of estimating evaporation. However, due to the complexity of input data of Penman's equa- 
tion and its neglectance of the heat storage in the case of deep lakes, several modifications have been proposed. Recent results by Warnaka \& Pochop (1988) suggested that approaches by Kohler et al. (1955), by Priestley \& Taylor (1972), by Stewart \& Rouse (1976) and by de Bruin (1978) might be expected to be most promising for an intercomparison under tropical conditions.

In the tropics the main problems faced with inputs into the Penman equation are routine measurements of wind speed and humidity (Stigter et al., 1989). Therefore Stigter et al. (1984) and Ibrahim et al. (1989a) proposed the replacement of the aerodynamic term in Penman's equation with a relation developed between shaded Piche evaporation and the aerodynamic term. Such relations were shown by Ibrahim et al. (1989a) to yield good results for a reference crop at Wad Medani (Sudan).

\section{Materials and methods}

Studies of lake evaporation were carried out with respect to Lake Sennar (Sudan), located in the tropics. Back waters of the reservoir extend up to $70 \mathrm{~km}$ southward of Sennar dam. The maximum surface area is about $160 \mathrm{~km}^{2}$ at full retention level. The lake has a maximum width of $4 \mathrm{~km}$ and a mean depth of about $4 \mathrm{~m}$ at full retention level. Water from Lake Sennar is largely used to supply irrigation water to the Gezira and Managil Irrigation Schemes and for power generation.

Three meteorological stations were used for the purposes of the study: on the lake, at the shore and the regular meteorological station. At each of the stations the following project equipment was used:

- thermohygrograph to measure air temperature and relative humidity,

- anemograph (or anemometer) to measure wind speed,

- shaded Piche evaporimeter to measure evaporation rates.

Incident radiation was measured by the upper side of an electrical solar albedometer, used as a solarimeter after a float accident and installed on a roof top in Sennar town. Readings from this instrument are taken as representative for the three measuring sites, which is allowed for most tropical network densities. All equipment was calibrated and recalibrated within the project.

The maximum input equation used was that of Penman (1956), with in the aerodynamic term its revised wind function over water as selected by Stigter (1980). This was compared with calculations using:

1. the same equation with the aerodynamic term replaced by correlations with shaded Piche evaporimeters,

2. approaches by Kohler et al. (1955),

3. the Priestley \& Taylor equation (1972),

4. de Bruin's (1978) approach as derived from the Priestley \& Taylor equation,

5. the Stewart \& Rouse (1976) equation.

Where applicable for the calculations, original wind functions were used in the various equations. Heat storage was neglected in all computations, as is commonly done for shallow lakes (e.g. Kohler et al., 1955; Penman, 1956). Moreover, tropical lakes tend to have a lower degree of thermal stratification due to less seasonal temperature fluctuations. 
Because of the limited period for which data were available and (mostly randomly) missing data in the data sets at the three Sennar stations, attempts were made to generate missing data by mutual correlations of basic parameters (air temperature, relative humidity, wind speed) and Piche evaporation between the three measuring sites. Only Piche evaporation correlations between stations were successful, when taking small standard errors of estimating the value at one station from a simultaneously measured one at the other as a yardstick. Because simple correlations could not be used for generating missing data other than Piche values, the limited basic data set had to be scrutinized for reliability. Because the data for the period February to May appeared intrinsically the most reliable, this period has been selected for comparing the different approaches. Measured routine data and measured and generated Piche evaporation rates were subsequently used to calculate evaporation rates from the three stations.

\section{Results and discussion}

Based on the good results for a reference crop as published by Ibrahim et al. (1989a), the same Wad Medani data input for fourteen months was used to obtain Figure 1 for the different case of open water, so now with the selected wind function for open water instead of a reference crop (Stigter, 1980). The correlation results

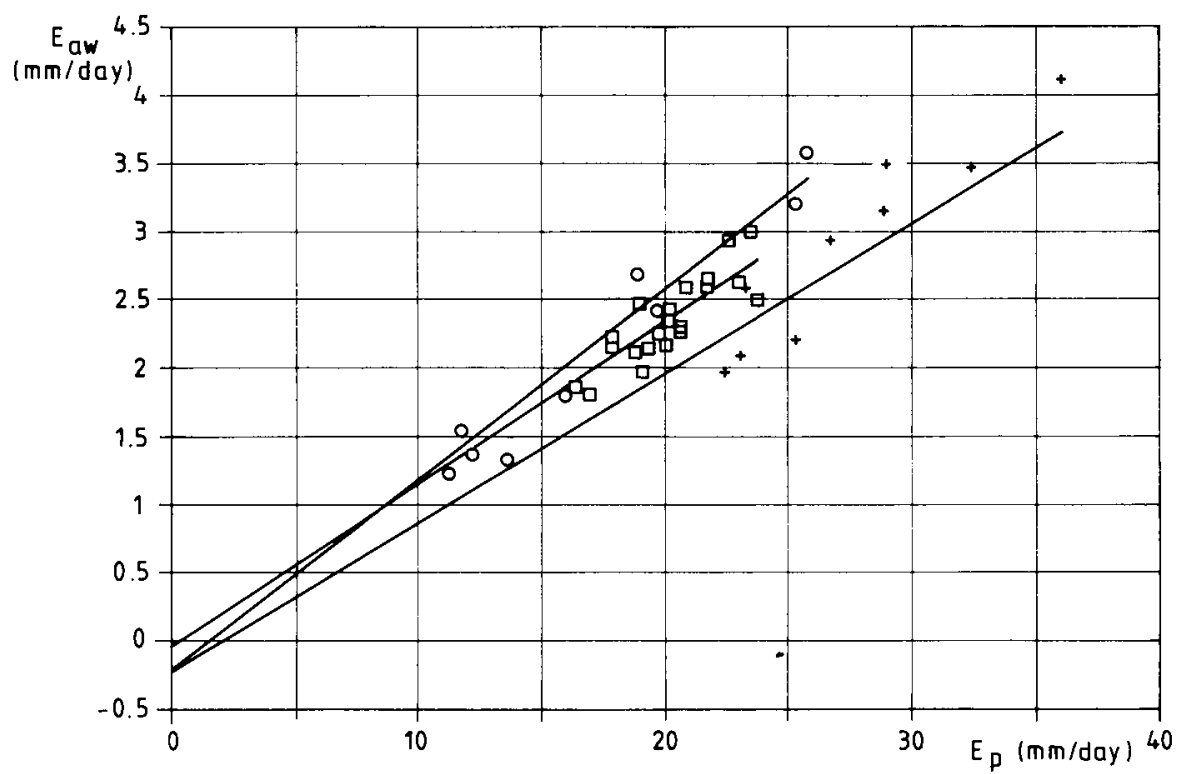

Fig. 1. Correlations between aerodynamic term in the Penman equation for open water $\left(E_{\text {aw }}\right)$ and shaded Piche evaporation $\left(E_{\mathrm{p}}\right)$ for three periods in Wad Medani (Sudan). For the period Feb-April, the correlation parameters are: $a=0.23 \mathrm{~mm} \mathrm{~d}^{-1} ; b=0.11 ; r=0.97$. व (Oct-Jan), + (Feb-Apr), o (JulSep). 
showed the power of using shaded Piches, also in this case, and allowed us to use the same approach for the much shorter time span of four months selected at Sennar. The Sennar calculations indicate that, although correlations differed somewhat for different inputs (Table 1), the correlations remain high. Estimates of evaporation rates for all sites using our proposed equation give differences within $\pm 2 \%$ of the estimates of Penman's equation in the period February to May, including the cases where Piche data were generated from correlations with other stations. One should of course note that these evaporation results have not been verified with independent data for the same period of the year.

Of the compared equations, the Stewart \& Rouse equation gives on the average results closest to Penman's evaporation estimates of $-13 \%$ using lake meteorological data, $-7 \%$ using shore data and $+17 \%$ using meteorological station data. As the Stewart \& Rouse approach only requires radiation energy (which is the same for all three stations) for the estimation of evaporation rates, the differences above reflect the variation of the aerodynamic term input data (wind speed and to a lesser degree relative humidity) among the three stations. Fetch problems are inherent (at varying extents) at the shore station and at the regular meteorological station. The location of the shore station was decided for the reason of equipment safety, but the place is open from NE and SW, the prevailing wind directions. However, because of the changing water levels and lake dimensions there is an inherent fetch problem of unknown influence that remains unsolved. At the regular meteorological station NE winds are unacceptably modified (that is: reduced) by an upwind area of houses protected by trees, with heights between 5 and $10 \mathrm{~m}$, at less than $100 \mathrm{~m}$ from the station. So the most reliable input gives an average difference of $-10 \%$.

The Kohler et al. approach, if the net radiation is computed, gives for the lake station $-16 \%,-15 \%$ for the shore station and $-13 \%$ for the routine meteoro-

Table 1. Correlation between the aerodynamic term $\left(E_{\mathrm{aw}}\right)$ and the shaded Piche evaporation $\left(E_{\mathrm{p}}\right)$. The correlation parameters of the equation $E_{\mathrm{aw}}=a+b E_{\mathrm{p}}$ are given for the dry period February to May, for different combinations of data from the three Sennar stations used. Combinations of data from the same station (cases 1, 5 and 9) are all measured data. In the other cases Piche data from the second mentioned station have been used to generate through established correlations Piche data for the first mentioned one.

\begin{tabular}{lccc}
\hline Combination & $a\left(\mathrm{~mm} \mathrm{~d}^{-1}\right)$ & $b$ & $r$ \\
1. Met.st.data/met.st.Piche & & & \\
2. Shore data/met.st.Piche & 0.30 & 0.12 & 0.96 \\
3. Lake data/met.st.Piche & 0.34 & 0.14 & 0.97 \\
& & & 0.97 \\
4. Met.st.data/shore Piche & -0.10 & 0.10 & 0.96 \\
5. Shore data/shore Piche & 0.23 & 0.12 & 0.98 \\
6. Lake data/shore Piche & 0.27 & 0.13 & 0.98 \\
7. Met.st.data/lake Piche & & & \\
8. Shore data/lake Piche & -0.12 & 0.11 & 0.96 \\
9. Lake data/lake Piche & 0.06 & 0.13 & 0.98 \\
\hline
\end{tabular}


logical station data with respect to Penman's estimates. The deviations from Penman's estimates are much larger (in the order $-30 \%$ to $-10 \%$ ) when the graphical approach of Kohler et al. is applied. The difference between the graphical solution and the computed solution is due to the assumption on the estimation of net radiation.

With Priestley \& Taylor and de Bruin equations, appreciable deviations from Penman's estimates were in two divergent ways. Priestley \& Taylor underestimate in the order of $40 \%$ while de Bruin overestimates the Penman evaporation rates by up to $50 \%$.

An important preliminary result with respect to availability of Nile water is that our Sennar evaporation data calculated with the Penman approach show an appreciably lower value for lake evaporation than the formula $E=0.5 E_{\mathrm{pr}}$ (where $E$ is lake evaporation and $E_{\mathrm{pr}}$ is evaporation from a routine Piche within a Stevenson screen), presently applied in Sudan. This is true for the data of all three stations and varies for our selected period from the order of $1.5 \mathrm{~mm} \mathrm{~d}^{-1}$ for lake data input to $4 \mathrm{~mm} \mathrm{~d}^{-1}$ for Sennar meteorological station data input, with its reduced air movement.

In conclusion, our results indicate that the proposed simplification of the Penman equation holds high promise for future tropical shallow lake evaporation calculations. The use of wind speed and humidity data will be eliminated and only the much easier shaded Piche evaporation measurements are needed together with the (weighted) radiation term. The Stewart \& Rouse equation also holds promise for this concept of minimum meteorological input approach. The original Penman equation (eventually with and without estimated storage terms), our proposed equation and the Stewart \& Rouse equation have therefore been selected for longer term testing, at lake Sennar and other Sudanese lakes, to improve evaporation calculations and water availability estimations.

\section{Acknowledgements}

The Netherlands Government offered a scholarship to the principal author and its Ministry of Foreign Affairs (DGIS/DPO/OT) is acknowledged for funding the TTMI-Project in its cooperation with the Gezira University (Wad Medani, Sudan). We thank the staff of the Ministry of Irrigation (Sudan), especially its Hydraulics Research Station (Wad Medani) and Sennar Dam Management. Ir K. Roscher, Department of Irrigation and Civil Engineering, Wageningen Agricultural University, is thankfully acknowledged as technical co-supervisor of the thesis.

\section{References}

Bruin, H. A. R. de, 1978. A simple model for shallow lake evaporation. Journal of Applied Meteorology 17: $1132-1134$

Ibrahim, A. A., C. J. Stigter, A. M. Adeeb, H. S. Adam \& A. E. Jansen, 1989a. Development and validation of a shaded Piche evaporimeter for the tropics to replace humidity and wind speed data in the aerodynamic term of the Penman equation. Proceedings of the fourth WMO Technical Conference on Instruments and Methods of Observation (TECIMO IV), Instruments and Observing Methods Report No 35, WMO TD-No 303, Geneva, p. 147-152. 
Ibrahim, A. A., H. S. Adam, A. Adeeb \& C. J. Stigter, with the collaboration of B. I. Abdulai, 1989 b. Evaporation from Sennar reservoir. Report No IIRC 2. Ford Foundation meeting in the Sudan on 'Irrigation Management in the Gezira Scheme', 34 pp. + Appendix, Hydraulics Research Station (coordinator), Wad Medani.

Kohler, M. A., T. J. Nordenson \& W. E. Fox, 1955. Evaporation from pans and lakes, US Weather Bureau Research Paper 38, 21 pp.

Penman, H. L., 1956. Evaporation: an introductory survey. Netherlands Journal of Agricultural Science 4: 9-29.

Priestley, C. H. B. \& R. J. Taylor, 1972. On the assessment of the surface heat flux and evaporation using large-scale parameters. Monthly Weather Review 100: 81-92.

Stewart, R. B. \& W. R. Rouse, 1976. A simple method for determining the evaporation from shallow lakes and ponds. Water Resources Research 12: 623-628.

Stigter, C. J., 1980. Assessment of the quality of generalised wind functions in Penman's equations. Journal of Hydrology 45: 321-331.

Stigter, C. J., C. B. S. Uiso \& A. M. G. M. Rashidi, 1984. Evaporation data from a Piche evaporimeter - a comment using Tanzanian results. Journal of Hydrology 73: 193-198.

Stigter, C. J., T. M. Hyera \& Y. B. Mjungu, 1989. Errors in routine humidity data from Tanzanian stations and their consequences. Proceedings of the Fourth WMO Technical Conference on Instruments and Methods of Observation (TECIMO IV), Instruments and Observing Methods Report No 35, WMO TD-No 303, Geneva, 333-338.

Warnaka, K. \& L. Pochop, 1988. Analysis of equations for free water evaporation estimates. Water Resources Research 24: 979-984.

This synopsis is based on a M.Sc.-thesis entitled 'Evaporation calculations from Lake Sennar (Sudan): a search for a meteorological minimum input approach' by B. I. Abdulai, MSc-course in Soil Science and Water Management, Wageningen Agricultural University, Wageningen, 1989, 93 pp., 14 tables, 31 figs., 65 refs., 9 app., in English. Available as paper copy (order R106, $f$ 30, - including postage, free for developing countries) at NARD, c/o Pudoc, P.O. Box 4, 6700 AA Wageningen (telex 45015 bluwgnl). 